\title{
Requirements Based Estimation Approach For System Engineering Projects
}

\author{
Radek Silhavy, Petr Silhavy and Zdenka Prokopova \\ Tomas Bata University in Zlin, \\ nám. T. G. Masaryka 5555, \\ 76001 Zlín, Czech Republic \\ phone: +420 57603 5015; email: rsilhavy@fai.utb.cz.
}

\begin{abstract}
In this paper the requirements are used for the purpose of the estimation. Requirements are cluster according to their complexity. The new approach in the papers is based on requirements analysis. The complexity of the requirements is set and Total Requirements Points Value (TRP) is calculated. The Total Requirements Points are modified by the technical and environmental factors, which described the problem domain and the development team experiences. The Total Requirements point can be used as a coefficient for the system size. According this approach system-engineering project can be compared and priced.
\end{abstract}

\section{INTRODUCTION}

The system engineering as a discipline covers a broad number of subject at present time. Military application [1], robotics [2], [5] or similar systems can be recognized as system in the scope of system engineering.

The system engineering has generic process. The process consists of five basic steps. These steps are requirements analysis, design, development, testing and validation. Requirements engineering is the first step and therefore takes key role in the whole system development

The methodology of the system estimation method for a system-engineering project is presented. The method is based on the clustered requirements approach [5], and by use case points method [3].

The use case points method [3], is an approach, based on the Use Case Model, which is uncommon in the System Modeling Language. The model is used for the system function description. The Use Case model is composed of the actors, which are external entity and of the use cases. The use cases represent system functions or algorithms. Each of the use case has to realize one of the requirements as minimum.

The Use Case is description of the activity of the action in the system. The use case model in the system engineering consists of the actors, use case and associations.

A use case is written in form of the scenario. The scenario represents sequence of the steps, which represents using of the system by an actor.

The actors and scenarios are the base factor in the estimation methodology, called use case points.

Scenarios provide a brief description of an activity of an actor in a system. Other common definition describes a scenario as internal part of a business process, which is solved by a system itself [4],

For purpose of estimation, number of steps in the scenario is significant [3]. The number of steps represents the scenario or use case complexity; therefore, a system complexity is represents by the number of use cases.

For analyzing the system, complexity is necessary to analyze the use cases, which were created based on requirements. The quality of use cases is important for the correct estimation without occurring errors.

The organization of this contribution is as follows. Chapter 2 describes the problem formulation. Chapter 3 describes the proposed method of the estimation. Chapter 4 and 5 describe technical and environmental factors. Chapter 6 describes calculation formulas. Chapter 7 describes a case study of the proposed methodology. Finally Chapter 8 is a conclusion.

\section{PROBLEM FoRMULATION}

The majority of well-known methods are based on similarity or on the use case model analysis. Creating the use case model is a complex task. Niche of the research is to preparation of the method, which will lead to estimation at very beginning of the development process.

The initial step of each development is called requirements analysis. As a result of the step the requirements definition document is created. In such document the system requirements can be found.

The system size, development time and development costs estimation is non-trivial task. This estimation is necessary for price negotiations. The system developers should have more précises method for pricing than Delphi method or experienced based methodologies. 
TABLE 1

COMPLEXITY LIST

\begin{tabular}{|c|c|}
\hline Complexity & Calculation Weight $\left(\mathrm{C}_{\mathrm{f}}\right)$ \\
\hline $\begin{array}{c}\text { Simple } \\
\text { Non-Functional RQ } \\
(\mathrm{NF})\end{array}$ & 5 \\
\hline $\begin{array}{c}\text { Average } \\
\text { System Characteristics } \\
(\mathrm{SC})\end{array}$ & 10 \\
\hline $\begin{array}{c}\text { Complex } \\
\text { Constrain RQ } \\
(\mathrm{CR})\end{array}$ & 15 \\
\hline
\end{tabular}

Therefore, in the following text, we are describing our algorithmic method, called system size estimation method.

\section{ESTIMATION APPROACH DEFINITION}

For the purpose of the estimation, the analysis of the requirements is necessary. The process of the estimation consists of following steps:

1) Set the importance of the requirement.

2) Set the complexity level of requirement.

3) Calculation of the Technical Factor.

4) Calculation of the Environment Factor.

The requirements are clustered into three groups. Complexity of the each group can be:

$$
\text { complexity }=\{\text { simple; } \text { avarage; } \text { complex }\}
$$

The simple set contains requirements, which have softwarebased implementation and are solved by 1 individual subsystem. Calculation weight value is 5 , as can be seen in the Table No. 1.

The average set contains requirements, which have hardware user interface or data processing. Calculation weight value is 10

The complex set contains requirements, which involves a technology control, mechanical user interface or very complex data processing. Implementation involves more than 1 subsystem. Calculation value is 15 .

The total value of parameters is calculated for each group:

Simple: $\sum(\mathrm{NF} \times \mathrm{Cf})$

Average: $\sum(\mathrm{SC} \times \mathrm{Cf})$

Complex: $\sum(\mathrm{CR} \times \mathrm{Cf})$

These values, when summed determines the Raw
Requirements Poins (RRP). According the following formula:

$$
\mathrm{RRP}=\sum(\mathrm{NF} \times \mathrm{Cf})+\sum(\mathrm{SC} \times \mathrm{Cf})+\sum(\mathrm{CR} \times \mathrm{Cf})
$$

\section{TECHNICAL FACTORS}

There are a 15 technical factor. These factors can be seen in the Table No. 2. The factor are revised version of the early published work [4].

The role of the impact is to provide a description of problem domain form technical point of view.

Each factor is weighted according to its relative impact. A weight of zero indicates the factor is irrelevant and the value 5 means that the factor has the most impact.

TABLE 2

TECHNICAL FACTORS

\begin{tabular}{|c|l|c|}
\hline TF & Description & Value $\left(\mathrm{V}_{\mathrm{e}}\right)$ \\
\hline T1 & Distributed Architecture & 2 \\
\hline T2 & Business Critical & 5 \\
\hline T3 & Performance & 1 \\
\hline T4 & End User Efficiency & 1 \\
\hline T5 & Complex Internal Processing & 1 \\
\hline T6 & Reusability & 1 \\
\hline T7 & Usability & 0,5 \\
\hline T8 & Safety & 5 \\
\hline T9 & Security & 1 \\
\hline T10 & Sociotechnical Aspect & 2 \\
\hline T11 & Modular Architecture & 2 \\
\hline T12 & Maintenance & 2 \\
\hline T13 & Upgradability & 2 \\
\hline T14 & Graphical User Interface & 5 \\
\hline T15 & Long LifeTime & 2 \\
\hline
\end{tabular}

Technical factors are used for Total Technical Factor value (TTV). Each TF values is multiple by value of its significance (TFs):

$\mathrm{TFs}=<0,10>$, for each $\mathrm{TF}$

Technical Factors Value (TFV) is calculated as follows:

$\mathrm{TFV}=\sum(\mathrm{TFs} \times \mathrm{Ve})$

As can be seen TFV represents weighed value of each TF (T1 - T15).

\section{ENVIRONMENTAL FACTORS}

Environmental Factors (EF) estimates the impact on productivity that various environmental factors have during the system development. Their role is describe development environment and moreover the problem domain itself.

The list of the proposed environmental factors can be seen 
in Table No. 3. The factors are evaluated and weighted according to its perceived impact and assigned a value between 0 and 10. A value of 0 means the environmental factor is irrelevant for this project; 5 is average; 10 means it has strong impact.

TABLE 3

ENVIRONMENTAL FACTORS

\begin{tabular}{|c|l|c|}
\hline EF & Description & Value $\left(\mathrm{V}_{\mathrm{e}}\right)$ \\
\hline E1 & System Designer Experience & 2 \\
\hline E2 & Domain Experience & 1 \\
\hline E3 & Modelling Experience & 2 \\
\hline E4 & Analysis Capability & 2 \\
\hline E5 & Motivation & 1 \\
\hline E6 & Stable Requirements & 2 \\
\hline E7 & Subcontractors & 5 \\
\hline E8 & Integration Complexity & 5 \\
\hline E9 & $\begin{array}{l}\text { Ecological Impact } \\
\text { (development) }\end{array}$ & 3 \\
\hline E10 & Public Importance & 1 \\
\hline E11 & Cost of the Shelf & 5 \\
\hline E12 & Regular Cooperation & -1 \\
\hline E13 & National Level Evaluation & 1 \\
\hline E14 & Methodology Experience & 5 \\
\hline E15 & Certification & 2 \\
\hline
\end{tabular}

Environmental factors are used for Total Environmental Factor value (EFV). Each EF value is multiple by value of its significance $(\mathrm{EFs})$ :

$\mathrm{EFs}=<0,10>$, for each EF

Environmental Factors Value (EFV) is calculated as follows:

$\mathrm{EFV}=\sum(\mathrm{EFs} \times \mathrm{Ve})$

As can be seen EFV represents summed weighed value of each EF (E1 - E15).

\section{Calculation formulas}

Final result of calculation, the Total Requirements Points (TRP) is calculated according following formula:

$\mathrm{TRP}=\mathrm{RRP} \times((\mathrm{CR} 1 \times \mathrm{TFV} / 100)+(\mathrm{CR} 2 \times \mathrm{EFV} / 100))$

Values CR1 and CR2 are use for tuning of the method. These values are set according the historical project measurement or statistical evaluation.

The TRP value represents the coefficient of the system size.

Project costs (PC) can be determined according following formula:

$$
\mathrm{PC}=\mathrm{TRP} \times \mathrm{PP}
$$

Where, Pp is price per on TRP. The value of the Pp is individual for each system engineering company.

The development time (DT) can be predicted in the similar way. Only the difference is that TRP is multiply by the coefficient of the man-hour per one TRP (MHP):

$$
\mathrm{DT}=\mathrm{TRP} \times \mathrm{MHP}
$$

\section{CASE STUdY}

The proposed methodology will be described on the sample project, which was adapted from [6].

In this sample is described development of the pocket audio player. The main important project goal was to offer a solution which was successfully in usability and which offers appropriate functionality.

The proposed requirements model can be seen in the Figure 1. The diagram illustrates hierarchical structure of the requirements. On the top of the tree the Specification package can be seen. Containment association interconnects other parts. The requirements are grouped in the four basic groups:

1. User Friendliness,

2. Durability,

3. Performance

4. Media Capacity.

The user friendliness group defines set of the requirements, which deal with quality of service of the audio player. Keys Layout, Graphical User Interface and Scroller are primary requirements, which take important role in user satisfaction. 


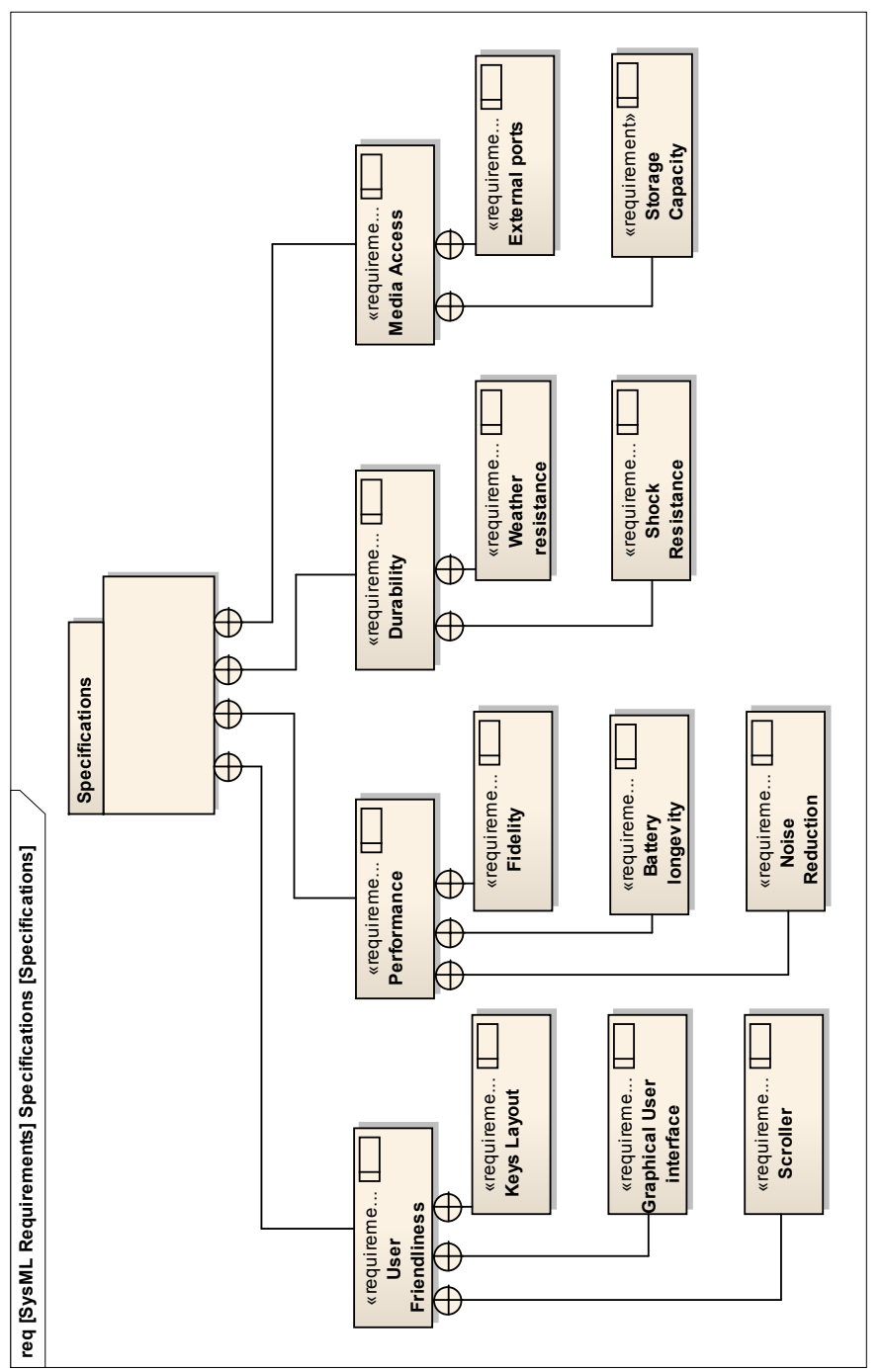

Fig 1: Sample System Engineering Project

In the project can be found 14 requirements. These requirements can be clustered in the simple, average or complex group:

Simple: 5

Average: 5

Complex 4

Complexity for each groups can be calculated as follows:

Simple: $\sum(5 \times 5)$

Average: $\sum(5 \times 10)$

Complex: $\sum(4 \times 15)$

The Raw Requirements Points are:

$\mathrm{RRP}=25+50+60$

$\mathrm{RRP}=135$

The next step is to prepare the Technical Factors and Environmental Factors. The table 2 and 3 will be used. TFs and EFs values have to be set.

In the table 4 there can be found the significance levels for
TABLE 4

TECHNICAL FACTORS SIGNIFICANCE

\begin{tabular}{|c|l|c|c|}
\hline TF & Description & $\left(\mathrm{V}_{\mathrm{e}}\right)$ & TFs \\
\hline T1 & Distributed Architecture & 2 & 0 \\
\hline T2 & Business Critical & 5 & 0 \\
\hline T3 & Performance & 1 & 10 \\
\hline T4 & End User Efficiency & 1 & 10 \\
\hline T5 & Complex Internal Processing & 1 & 5 \\
\hline T6 & Reusability & 1 & 0 \\
\hline T7 & Usability & 0,5 & 10 \\
\hline T8 & Safety & 5 & 2 \\
\hline T9 & Security & 1 & 0 \\
\hline T10 & Sociotechnical Aspect & 2 & 5 \\
\hline T11 & Modular Architecture & 2 & 0 \\
\hline T12 & Maintenance & 2 & 0 \\
\hline T13 & Upgradability & 2 & 0 \\
\hline T14 & Graphical User Interface & 5 & 6 \\
\hline T15 & Long LifeTime & 2 & 4 \\
\hline
\end{tabular}

the each of the Technical factors.

The Technical Factors Value (TFV) is calculated according the formula $\left(\sum(\mathrm{TFs} \times \mathrm{Ve})\right)$. For the case study the $\mathrm{TFV}=88$.

In the table 5 can be found the Environmental Factors. There can be seen the (EFs) values of the significances of the environmental factors.

TABLE 5

ENVIRONMENTAL FACTORS SIGNIFICANCE

\begin{tabular}{|l|l|c|c|}
\hline TF & \multicolumn{1}{|l|}{ Description } & $\left(\mathrm{V}_{\mathrm{e}}\right)$ & EFs \\
\hline E1 & System Designer Experience & 2 & 0 \\
\hline E2 & Domain Experience & 1 & 5 \\
\hline E3 & Modelling Experience & 2 & 5 \\
\hline E4 & Analysis Capability & 2 & 4 \\
\hline E5 & Motivation & 1 & 4 \\
\hline E6 & Stable Requirements & 2 & 0 \\
\hline E7 & Subcontractors & 5 & 0 \\
\hline E8 & Integration Complexity & 5 & 5 \\
\hline E9 & Ecological Impact & 3 & 0 \\
\hline E10 & Public Importance & 1 & 0 \\
\hline E11 & Cost of the Shelf & 5 & 0 \\
\hline E12 & Regular Cooperation & -1 & 10 \\
\hline E13 & National Level Evaluation & 1 & 2 \\
\hline E14 & Methodology Experience & 5 & 4 \\
\hline E15 & Certification & 2 & 1 \\
\hline
\end{tabular}


The EFV value - according the table 5 is 66 .

Final result of calculation, the Total Requirements Points (TRP) is calculated according following formula 10 :

$\mathrm{TRP}=135 \times((0.7 \times 88 / 100)+(0.5 \times 66 / 100))$.

Total Requirements Points are: 83.43

Values CR1 is set to 0,7 and CR2 is set to 0,5 . These values are based on average values of the correction values - based on empirical research, which based the historical project measurement evaluation.

Project cost for the sample project is:

$\mathrm{PC}=83.49 \times 8500$, where $\mathrm{PP}$ in $(11)$ is in undefined currency. The result is 709665 .

The development time (DT) can be predicted in the similar way.

$\mathrm{DT}=83.49 \times 100$. This resulted in 8349 man-hour for the proposed project.

For this calculation can be used an excel table or specific software tool. The proposed tool is CompuEstimator. In the figure 2 can be found the sample of the user interface of the application.

\section{CONCLUSION}

In this paper the requirements were used for the system estimation. The estimation method for the system engineering projects were introduced.

The method is inspirited by methods used in the field of software engineering. This methods is based on the Use Case model. For the purpose of the system engineering the estimation is based on the requirements analysis.

Further research in the project estimation is firstly focused of the appropriate calculation values CR1,2.

Secondly improving accuracy of technical and environmental factors. Thirdly we will investigate method of artificial intelligence for tuning correction factors and weights for technical and environmental factors.

\section{REFERENCES}

[1] R. J. Vidmar. (1992, August). On the use of atmospheric plasmas as electromagnetic reflectors. IEEE Trans. Plasma Sci. [Online]. 21(3). pp. 876-880. Available: http://www.halcyon.com/pub/journals/21ps03vidmar [1] Balla, J. 2011, Dynamics of mounted automatic cannon on track vehicle. International Journal of Mathematical Models and Methods in Applied Sciences, Vol. 5, No. 1, page numbers (423-432), ISSN 1998-0140

[2] Ciulanescu, M. V. \& Diaconu, A. (2009). Mobile Robot Control using the Bluetooth Technology, Annals of DAAAM for 2009 \& Proceedings of the 20th International DAAAM Symposium, 25-28th November 2009, Vienna, Austria, ISSN 1726-9679, ISBN 978-3-901509-70-4, Katalinic, B. (Ed.), pp. 1115-1116, Published by DAAAM International Vienna, Vienna

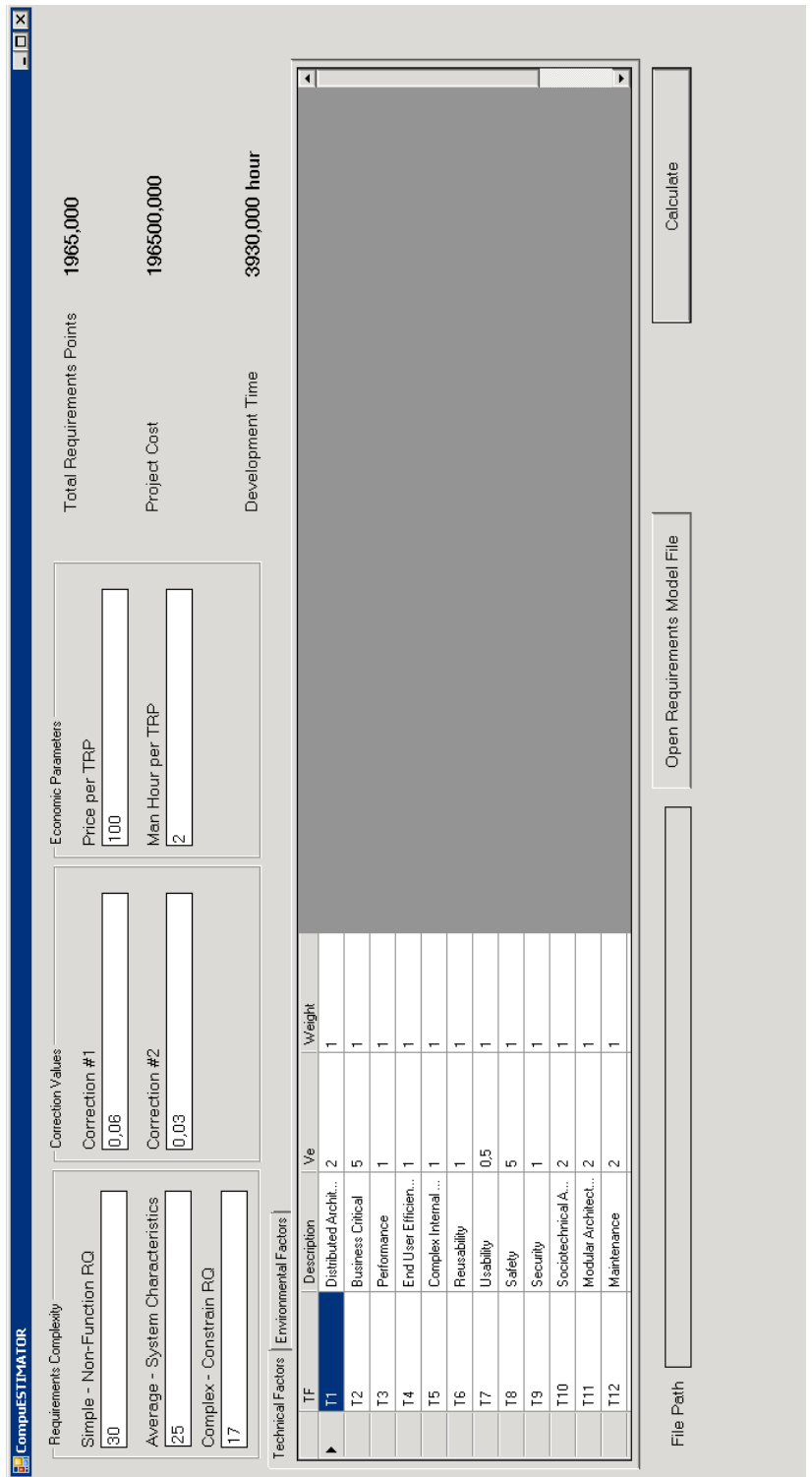

Fig 2: CompuESTIMATOR Software Tool

[3] Ribu, K. (2001) Estimating Object-Oreinted Software Projects with Use Case. Unvirstiy in Oslo, Oslo.

[4] Silhavy R., Silhavy P. \& Prokopova, Z. (2011). Clustered Requirements in System Engineering Project Estimation. Internatinal Journal of Mathematical models and Methods in Applied Sciences, Vol. 5, No. 1, (June 2011) page numbers (1052-1059), ISSN 1998-0140

[5] Quarda, H. 2011. Cognitive tasks behavior of intelligent autonomous mobile robots, International Journal of Mathematical Models and Methods in Applied Sciences, Vol. 5, No. 3, page numbers (610-619), ISSN 1998-0140

[6] Silhavy, R, Silhavy, P, Prokopova, Z. Systematic modeling process of system behavior. International Journal of Mathematical Models and Methods in Applied Sciences [online]. 2011, vol. 5, iss. 6, s. 1044-1051. [cit. 2012-10-08]. ISSN 1998-0140. 